\title{
A systematic review of the main approaches to catheterization/coronary angioplasty by a distal radial artery in the anatomical snuffbox
}

\author{
Dr. Idiberto Jose Zotarelli Filho, MSc, Ph.D ${ }^{1}$ \\ ${ }^{1}$ Affiliation not available
}

May 28, 2020

\begin{abstract}
Introduction: In the scenario of cardiovascular disease (CVD), the WHO reported in 2017 that there are about 21.7 million deaths, of which more than ten million are due to atherosclerotic coronary disease. In Brazil, CVD is responsible for about 384 thousand deaths per year. Arterial access for coronary angiography and percutaneous coronary interventions has addressed the change from the transfemoral to the transradial (TRA) pathway, as this presents fewer complications, especially the distal transradial pathway (dTRA) in the anatomical snuffbox. Objective: To carry out a systematic review of the main snuffbox approaches. Methods: Review papers, systematic reviews, prospective studies, retrospective studies, clinical trials, and case reports were selected. The MeSH Terms were the Radial artery. Catheterization. Percutaneous coronary intervention. Of the total of 105 articles found, 23 studies were selected, following the rules of PRISMA. Results: The studies analyzed showed that dTRA is a reliable, safe, effective and comfortable route. The position of the arm during the intervention is comfortable for the patient, who does not need to expose the palm side of the arm while flexing the arm towards the operator. The studies also reported that there is a low rate of obstruction of the distal radial artery. There is also early hemostasis, low risk of hematoma formation, low level of pain perceived by patients, reduced risk of compartment syndrome, saving the radial artery for possible future myocardial revascularization grafting, and the operator's ability to work at a safe distance of the radiation source. The average success rate in the studies analyzed was $97 \%$. The average rate of occlusion of the distal radial artery was $0.5 \%$. Other complications at the access site were hematoma $(0.2 \%)$, pulsatile hematoma $(<0.1 \%)$, infection $(0.1 \%)$, dissection $(0.1 \%)$, arteriovenous fistula $(<0.1 \%)$. Conclusion: Distal radial access is a reliable, safe, effective, and comfortable route for cardiovascular interventions. They have a less arterial obstruction and short hemostasis. The main disadvantage is the difficulty in cannulation. However, more randomized studies and meta-analysis are needed to establish a guideline.
\end{abstract}

Keywords: Transradial artery. Distal transradial artery. Left distal transradial artery. Catheterization. Percutaneous coronary intervention.

Otávio Queiroz Assumpção ${ }^{1}$, Vanessa Piovesan Freitas Assumpção ${ }^{1}$, Pedro Wagner Ramos Júnior $^{2}$, Marcos Eduardo dos Santos Dotto ${ }^{3}$, Francisco Corrêa de Almeida Moraes ${ }^{4}$, Antonio Carlos Broim Pancotti ${ }^{5}$, Caio Fraga Barreto de Matos Ferreira ${ }^{6}$, Jaquelini Tirapelle Ayub Ribeiro $^{7}$, Viviane Ferreira Gali ${ }^{8}$, Idiberto José Zotarelli Filho ${ }^{9,10}$, Luiz Antonio Gubolino, 11,12,13

1 Fundação Hospitalar de Costa Rica Clínica Vitale (ICCOR)/Costa Rica Hospital Foundation- Vitale Clinic, Costa Rica-MS, Brazil.

2 Hospital Beneficência Portuguesa/ Beneficência Portuguesa Hospital, São José do Rio Preto-SP, Brazil.

3 Clinica Dottor's, Ambulatório Médico de Especialidade- AME, Clínica Prevencardio Exames/ Dottor's Clinic, Ambulatory Medical Specialty Votuporanga e Jales-SP, Brazil. 
4 Instituto MS-COR/MS-COR Institute, Catanduva-SP, Brazil.

5 Clínica Pancor e Centro De Cardiologia Avançado/ Pancor Clinic and advanced Cardiology Center - Santa Casa De Fernandópolis-SP, Brazil.

6 Santa Casa Hospital, Lins-SP, Brazil.

7 Ambulatório Médico de Especialidade-AME/ Ambulatory Medical Specialty Votuporanga-SP, Brazil.

8 Unimar Hospital, Marília-SP, Brazil.

9 Zotarelli-Filho Scientific Work, São José do Rio Preto/SP, Brazil.

10 FACERES - Medical School of Sao Jose do Rio Preto/SP, Brazil.

11 Instituto do Coração do Hospital de Piracicaba (INCORPI)/ Heart Institute of Piracicaba Hospital, Piracicaba-SP, Brazil.

12 INCOR Rio Preto, São José do Rio Preto-SP, Brazil.

13 AUSTACOR - Austa Hospital, São José do Rio Preto-SP, Brazil.

Corresponding Author: Idiberto José Zotarelli Filho, MsC, Ph.D. FACERES- Medical School, São José do Rio Preto SP, Brazil; email: m.zotarelli@gmail.com.

\section{Introduction}

According to the World Health Organization (WHO), cardiovascular disease (CVD) is the leading cause of death in the world. It is estimated that 17.7 million people died from CVD in 2015, representing 31\% of all deaths globally. In addition, more than three quarters, about $37 \%$, of CVD deaths occur in low- and middle-income countries, and, in Brazil, CVD is responsible for about 384 thousand deaths per year [1].

In this context, prophylactic and reparative cardiovascular interventional measures using angioplasty and catheterization techniques are necessary. Thus, the use of the radial artery as an access route for diagnostic procedures in cardiology was first described in the literature by Lucien Campeau in 1989 [2]. Afterward, Kiemeneij published the first three patients submitted to angioplasty with stenting by this route [3]. Then, in 1997, the same author published the ACCESS study [4], comparing the coronary intervention of the radial, brachial, and femoral accesses. As the main clinical outcomes of the use of the radial artery route, an important reduction in hemorrhagic complications were found. In addition, this safety profile has also been demonstrated in patients with acute coronary syndromes [4].

Therefore, the access by transradial approach (TRA) is consolidated through studies that show a positive association between this path and the reduction in cardiac mortality, mediated by a lower rate of vascular complications, including in patients undergoing primary and primary angioplasty. rescue [5-8]. As scientific evidence of this, a retrospective analysis of the British Columbia Database of cardiac and renal records showed that progression to chronic renal failure after six months of cardiac catheterization occurred in $0.2 \%$ of those who underwent the TRA procedure [9].

In this sense, the distal transradial approach (dTRA) was advocated to reduce the risk of occlusion of the radial artery in the forearm, preventing reintervention through the same access site and complications at the bleeding and vascular site $[10,11]$. In addition, dTRA is also the main site for retrograde recanalization of radial artery occlusion. According to Kaledin et al., The flow of anterograde blood would be preserved through the superficial palmar arch (snuffbox), thus, the risk of thrombosis and occlusion of the extensive radial artery in the forearm would be minimized [12]. In addition, this arterial entry is beyond the forearm compartments, reducing the risk of compartment syndrome. Finally, the dTRA provides better operator and patient comfort, especially when using the left radial approach (ldTRA) [12].

Therefore, the present study aimed to carry out a systematic review of the main considerations of prophylactic and reparative cardiovascular interventional procedures through the distal transradial approach in the 
anatomical snuffbox.

\section{METHODS}

\section{Study design}

This study will follow the international model of Systematic Review and Meta-analysis, following the rules of PRISMA (preferred reporting items for systematic reviews and meta-analysis) [19].

Table 1 shows the main variables of the present study that will be addressed according to the classification of the acronym PICO ( $\mathrm{P}=$ Patients; $\mathrm{I}=$ Intervention; $\mathrm{C}=$ Control; $\mathrm{O}=$ Outcomes $)$.

Table 1. PICO chart (Patients; Intervention; Control; Outcomes).

\begin{tabular}{ll}
\hline PATIENTS & Cardiovascular diseases Coronary heart disease \\
Intervention & Distal transradial artery Left distal transradial \\
& artery \\
CoNTROL & Results among the studies covered \\
Outcomes & Procedure success rate Main difficulties \\
& Complications Patient satisfaction Quality of life \\
& analysis \\
\hline
\end{tabular}

\section{Study eligibility criteria}

The inclusion criteria will be articles that present adult patients and both sexes previously submitted to. Exclusion criteria will be articles that present another procedure for erosion or removal of the ring other than through stents and endoscopic procedures, respectively.

\section{Selection of studies and risk of bias}

The study selection was be evaluated by two independent reviewers. Reviewer 1 was perform data extraction and Reviewer 2 will analyze that data. A third investigator was make the final decision to choose the articles and decide on conflicting points. The Cochrane instrument was be adopted to assess the quality of the included studies (Higgins 2011) [20].

A total of 105 articles were found with the mentioned Mesh Terms, and after the selection criteria in Table 1 above, 25 studies were selected and 23 scientific articles were analyzed in full to compose the present study.

\section{Data sources and research strategy}

The search strategies for this systematic review was be based on the descriptors (MeSH Terms) "Transradial artery. Distal transradial artery. Left distal transradial artery. Catheterization. Percutaneous coronary intervention", with publications from 1989 to 2020, in order to analyze the most recent scientific publications. The research will be carried out in June 2020 and developed at SCOPUS (Elsevier and non-Elsevier database), PUBMED (MEDLINE biomedical literature, life science magazines, and online books) and SCIENCE DIRECT (Elsevier database), including the National Institutes of Health RePORTER Grant database and clinical trial records. In addition, a combination of the keywords with the Booleans "OR", AND and the operator "NOT" was be used to target scientific articles of interest. The title and abstracts will be examined under all conditions. The research structure used in the databases is shown in Table 2.

Table 2. Example of the research structure in PubMed, the same search strategy was used in the other databases.

PubMed Transradial access OR distal transradial approach OR Transradial artery OR Distal transradial artery OR Left AND

PubMed Catheterization OR angioplasty OR Percutaneous coronary intervention OR Snuffbox anatomical OR Follow $\mathrm{O}$ 
PubMed Transradial access OR distal transradial approach OR Transradial artery OR Distal transradial artery OR Left NOT

PubMed Femoral radial artery OR Conventional angioplasty

\section{Discussion}

The access of the dTRA in the anatomical snuffbox was initially described with the objective of recanalization of occluded retrograde radial arteries [13,14], being proposed as an alternative route of arterial access, aiming to preserve the radial artery and for possible surgical procedures. In 2017, Kiemeneij [13] arouses scientific curiosity with the publication of a series of 70 patients in which diagnostic catheterization or coronary intervention was performed by left distal transradial puncture (ldTRA). Although there were 8 puncture failures (11.4\%), the remaining 62 patients did not impose major difficulties or report significant discomfort during the exam.

In the Babunashvili and Dundua series of 637 patients with radial access, 9 the anatomical snuffbox was used in $92 \%$, only $11 \%$ were PCI procedures and the sheath size was $5 \mathrm{~F}$ in $91 \%$ and $6 \mathrm{~F}$ in $9 \%$. The overall success rate was $98 \%$. Radial artery occlusion rate was $0 \%$ acute and $0.2 \%$ late (more than 3 months) follow-up [11].

In addition, a study published by Kaledin et al. [12] presented 2,884 patients undergoing endovascular surgery interventions, 10 the anatomical snuffbox was used in $96 \%$ of the patients, $93.5 \%$ of the interventions were PCI procedures, with a $6 \mathrm{~F}$ sheath in $98 \%$ and $7 \mathrm{~F}$ in $1 \%$. The success rate was $97 \%$. In the follow-up, the rate of occlusion of the radial artery at the access site with preserved blood flow from the radial artery of the forearm was observed in $2 \%$ cases; occlusion of the radial artery of the forearm after catheterization of the artery inside the anatomical snuffbox was observed in $0.4 \%$ of cases. This contrasts with the rate of occlusion of the radial artery of $4.2 \%$ observed by the same authors, using the traditional radial approach of the forearm. Other complications at the access site were similar to those observed with the forearm approach: hematoma $(0.2 \%)$, pulsatile hematoma $(<0.1 \%)$, infection $(0.1 \%)$, dissection $(0.1 \%)$, fistula arteriovenous $(<0.1 \%)$.

In addition, in the work of Roghani-Dehkordi et al. [15], a series of 235 patients with access to the anatomical snuffbox, $1329 \%$ were PCI procedures. The success rate was $94 \%$, the rate of asymptomatic radial artery occlusion at the site of access was about $1 \%$. In addition, of the 118 consecutive patients assigned to the Kiemeneij operation program, 70 patients $(40.7 \%)$ were considered suitable for ldTRA access. There were eight procedural flaws, requiring crossover to traditional right radial or left radial approach. All other procedures were successful (89\%), without great discomfort for the patient and operator. No occlusion of the radial artery at the forearm site was found.

Thus, according to these literary findings, Table 3 below presents the main considerations and advantages of dTRA and ldTRA.

Table 3. Importance of the distal and left radial approach.

IMPORTANCE OF THE DISTAL RADIAL APPROACH

To improve operator and patient comfort, catheterization, arteriovenous shunt, or collection for myocardial revascularization Short compression time, facilitating outpatient PCI.

Preservation of the radial artery in the forearm for future

The authors Kim et al. [16] published a series of 150 selected patients who had angiography or PCI with 6 French catheters via the left box approach, 14 success rate was $88 \%$. The main reasons were a failure in puncture and failure in advancing the guidewire due to the tortuosity of the artery and vasospasm. In the 
experience of Valsecchi et al. [17], all 52 patients underwent diagnostic or procedural intervention through dTRA access. The overall viability was $90 \%$. The failures occurred due to occlusion of the proximal radial artery and distal hypoplastic/vasospastic artery.

In the context of performing the puncture on the patient's left side, it does not impose additional difficulties [18]. An observation to be taken in these cases is that, when the patient has some degree of respiratory distress and uses abdominal breathing more intensely, there is a lot of hand oscillation at this time, which can prevent not the correct palpation of the wrist, but its puncture. As for the viability and incidence of complications, it has already been demonstrated that there are no differences between the two sides, despite the slight differences in favor of the radial left in terms of shorter fluoroscopy time and less volume of contrast used [21]. This small disproportion is not due to the fact that we find more tortuosity when navigating the Brachiocephalic Trunk, which does not occur on the left side [22].

An advantage of the dTRA route is to preserve the conventional local radial puncture system on the wrist, as the need for multiple procedures on the same patient is becoming more and more frequent, due to increased life expectancy, as well as increased comorbidities that contribute to the development of atherosclerotic disease [22]. There is no tissue or vascular trauma in the usual place, nor does it suffer the effects of prolonged hemostatic compression or even with excessive intensity. However, a relevant perception during patient selection was that, in many individuals who had a palpable radial pulse at the wrist, the pulse in the anatomical region. The snuff box region was very thin or imperceptible [22].

The disadvantage of the vessel's smaller caliber, which certainly decreases eligibility for the technique, has led us to assume that it may not be accessible to become a standard in cardiology interventions, but a good option in selected cases, especially on the left side. Another advantage that emerges from the present study is that the dTRA access security profile is similar to the conventional TRA profile since a minimal incidence of hemorrhagic complications was detected and there was no pulse loss [21].

The maintenance of the wrist appears as an interesting advantage due to the possibility of repeating the puncture in the same place, when necessary. Due to the similarity of the advantages of the two techniques, dTRA access can become another access route in which there will be the possibility of early discharge, even on the same day. Data from the Brazilian reality are already beginning to confirm the safety of this strategy, as long as an observation period is observed, approximately 6 hours are observed in selected patients [22].

The incidence of radial artery occlusion (RAO) and hemorrhagic events with dTRA has not been fully elucidated. Thus, a study in Japan investigated the effects of using dTRA on RAO and post-procedure hemorrhage. From April 2018 to July 2018, 228 consecutive patients undergoing coronary angiography or intervention through dTRA in two hospitals were analyzed. The rate of RAO, changes in the diameter of the forearm and distal radial artery, and cross-sectional area after the dTRA (1 day and 1 month) on vascular ultrasound and incidence of hemorrhagic complications were investigated. RAO in the forearm and distal occurred in $1(0.4 \%)$ and $8(3.1 \%)$ patients in 1 month, respectively. There were no bruises on the forearm. The ultrasound findings indicated that the diameter of the radial artery and the cross-sectional area was significantly larger after the dTRA $(\mathrm{p}<0.001)$. The diameter of the distal radial artery and the cross-sectional area in the anatomical snuffbox were also significantly larger after the dTRA ( $p<0.001)$. Therefore, dTRA was associated with a low incidence of RAO at the puncture site and in the forearm, post-procedure dilation of the radial artery, and no hemorrhagic complications that extended to the forearm [23].

In addition, the ldTRA approach is a new technique for coronary intervention. This technique is convenient for specialists to operate and is welcome for right-handed patients. The anatomical snuffbox and the first intermetacarpal are two puncture sites available based on the anatomy of the hand. In technical aspects, the main differences between the left distal transradial approach and the conventional transradial approach are the patient's special position, puncture procedure, choice of the sheath, and hemostasis methods. According to preliminary data, this technique is viable and safe and has a low rate of complications, including occlusion of the radial artery in the forearm. The left distal transradial approach is a very promising strategy for 
coronary intervention and deserves further exploration [24].

In addition, another study analyzed that dTRA is associated with reduced rates of radial artery occlusion, ischemic events in the hands, as well as greater patient comfort, faster periprocedural management, and cost benefits. Our preliminary experience with dTRA for diagnostic cerebral angiography demonstrates excellent viability and safety in combination with relative efficiency [25].

\section{Limitations}

The radial artery diameter was assessed by Kaledin et al. using ultrasound10: the average diameter was 2.4 $\mathrm{mm}$ in the anatomical snuff box, slightly smaller than the average diameter of $2.7 \mathrm{~mm}$ of the radial artery in the forearm. The puncture is therefore more challenging, and a learning curve must be overcome. In the Kiemeneij 11 series of patients, the distal radial artery was too weak to attempt a puncture in the radial fossa in $23 \%$ of cases. The dTRA technique is certainly not suitable for unselected patients, for the simple reason that, in a substantial number of patients, no clear pulse is palpable in the anatomical snuffbox.11 In addition, in complex PCI procedures that require greater guidance catheter diameter, a catheter without a sheath may be required. In addition, as the access site is more distal, regular catheters in length $(100 \mathrm{~cm})$ may be too short to cannulate the coronary arteries of tall patients and extra length catheters (110 or 115 $\mathrm{cm}$ ) may be necessary for these patients. Some hemostatic devices designed for forearm compression may be too short for distal radial access.

\section{Conclusion}

According to the main literary findings from the systematic review, the access of the dTRA in the anatomical region of the snuffbox proved to be safe and viable when performed by experienced operators. The method described in the literature is very reproducible in patients selected for catheterization and angioplasty. Once the puncture is obtained, the procedure follows the usual parameters of known access.

\section{Conflict of interests}

There is no conflict of interest between authors.

\section{References}

1. WHO-World Health Organization. Available in: https://www.paho.org/bra/index.php?option=com _content\&view $=$ article\&id=5253:doencas-cardiovasculares\&Itemid=1096. Accessed May 27, 2020.

2. Radner S. Thoracal aortography by catheterization from the radial artery. Acta Radiol. 1948;29:178180. 2. Campeau L. Percutaneous radial approach for coronary angiography. Cathet Cardiovasc Diagn. 1989;16:3-7.

3. Kiemeneij F, Laarman GJ. Percutaneous transradial artery approach for coronary stent implantation. Cathet Cardiovasc Diagn. 1993;30: 173-178.

4. Kiemeneij F, Laarman GJ, Odekerken D, Slagboom T, van der Wieken R. A randomized comparison of percutaneous transluminal coronary angioplasty by the radial, brachial and femoral approaches: the access study. J Am Coll Cardiol. 1997;29(6):1269-75.

5. Gubolino LA, Vieira WR, Bragalha AMLA, Soares M, Nogueira PR, Nogueira C. Intervenção coronária percutânea transradial. Rev Bras Cardiol Invasiva. 2000;8:27-32.

6. Agostoni P, Biondi-Zoccai GG, de Benedictis ML, Rigattieri S, Turri M, Anselmi M, Vassanelli C, Zardini P, Louvard Y, Hamon M. Radial versus femoral approach for percutaneous coronary diagnostic and interventional procedures; Systematic overview and meta-analysis of randomized trials. J Am Coll Cardiol. 2004;44(2):349-56.

7. 6Kinnaird TD, Stabile E, Mintz GS, Lee CW, Canos DA, Gevorkian N, Pinnow EE, Kent KM, Pichard AD, Satler LF, Weissman NJ, Lindsay J, Fuchs S. Incidence, predictors, and prognostic implications of bleeding and blood transfusion following percutaneous coronary interventions. Am J Cardiol, 92 (2003): 930-935.

8. 10Jolly SS, Yusuf S, Cairns J, Niemelä K, Xavier D, Widimsky P, Budaj A, Niemelä M, Valentin V, Lewis BS, Avezum A, Steg PG, Rao SV, Gao P, Afzal R, Joyner CD, Chrolavicius S, Mehta 
SR; RIVAL trial group. Radial versus femoral access for coronary angiography and intervention in patients with acute coronary syndromes (RIVAL): a randomised, parallel group, multicentre trial. Lancet. 2011;377(9775):1409-20.

9. Patel VG, Brayton KM, Kumbhani DJ, Banerjee S, Brilakis ES. Meta-analysis of stroke after transradial versus transfemoral artery catheterization. Int J Cardiol. 2013;168(6):5234-8.

10. Corcos T. Distal radial access for coronary angiography and percutaneous coronary intervention: A state-of-the-art review. Catheter Cardiovasc Interv. 2018;1-6. https://doi.org/10.1002/ccd.28016.

11. Babunashvili A, Dundua D. Recanalization and reuse of early occluded radial artery within 6 days after previous transradial diagnostic procedure. Cathet Cardiovasc Interv. 2011;77:530-536.

12. Kaledin AL, Kochanov IN, Podmetin PS, Seletsky SS, Ardeev VN. Distal radial artery in endovascular interventions, 2017. https://www. researchgate.net/.

13. Kiemeneij F. Left distal transradial access in the anatomical snuffbox for coronary angiography and interventions. EuroIntervention. 2017; 20:851-857.

14. Davies RE, Gilchrist IC. Back hand approach to radial access: The snuffbox approach. Cardiovasc Revasc Med. 2018;19:324-326.

15. Roghani-Dehkordi F, Hashemifard O, Sadeghi M, et al. Distal accesses in the hand (two novel techniques) for percutaneous coronary angiography and intervention. ARYA Atheroscler. 2018;14:95-100.

16. Kim Y, Ahn Y, Kim I, et al. Feasibility of coronary angiography and percutaneous coronary intervention via left snuffbox approach. Korean Circ J. 2018;48:e118.

17. Valsecchi O, Vassileva A, Cereda AF, et al. Early clinical experience with right and left distal transradial access in the anatomical snuffbox in 52 consecutive patients. J Invasive Cardiol. 2018;30:218-223.

18. Toledo JFBD, Gubolino LA,Teixeirense PT, Bragalha AMLA, Filho IJZ (2018) Diagnostic and Interventional Coronary Procedures by the Distal Radial Artery in the Anatomical SnuffBox: A Real World Analysis. J Cardiovasc Dis Diagn 6: 337. doi:10.4172/2329-9517.1000337.

19. Higgins J, Green S. Cochrane Handbook for Systematic Reviews of Interventions. Version 5.1.0 [updated March 2011]. The Cochrane Collaboration; 2011.

20. Amin MR, Banerjee SK, Biswas E, et al. Feasibility and Safety of Distal Transradial Access in the Anatomical Snuffbox for Coronary Angiography and Intervention. Mymensingh Med J . 2019;28(3):647654.

21. Wretowski D, Krakowian M, Labyk A, Pruszczyk P, Roik M. Very distal transradial approach (VITRO) for coronary interventions. Postepy Kardiol Interwencyjnej. 2019;15(1):42-45. doi:10.5114/aic.2019.83771.

22. Coomes EA, Haghbayan H, Cheema AN. Distal transradial access for cardiac catheterization: A systematic scoping review [published online ahead of print, 2019 Nov 29]. Catheter Cardiovasc Interv. 2019;10.1002/ccd.28623. doi:10.1002/ccd.28623.

23. Mizuguchi Y, Izumikawa T, Hashimoto S, et al. Efficacy and safety of the distal transradial approach in coronary angiography and percutaneous coronary intervention: a Japanese multicenter experience. Cardiovasc Interv Ther. 2020;35(2):162-167. doi:10.1007/s12928-019-00590-0.

24. Feng H, Fang Z, Zhou S, Hu X. Left Distal Transradial Approach for Coronary Intervention: Insights from Early Clinical Experience and Future Directions. Cardiol Res Pract. 2019;2019:8671306. Published 2019 Oct 31. doi:10.1155/2019/8671306.

25. Brunet MC, Chen SH, Sur S, et al. Distal transradial access in the anatomical snuffbox for diagnostic cerebral angiography. J Neurointerv Surg. 2019;11(7):710-713. doi:10.1136/neurintsurg-2019-014718. 